\title{
Efficacy and Safety of Bitopertin in Patients with Schizophrenia and Predominant Negative Symptoms: Subgroup Analysis of Japanese Patients from the Global Randomized Phase 2 Trial
}

\author{
Yoshio Hirayasu ${ }^{1}$, Shin-Ichi Sato ${ }^{2}$, Norifumi Shuto ${ }^{2}$, Miwa Nakano², and Teruhiko Higuchi ${ }^{3}$ \\ 1'Department of Psychiatry, Yokohama City University Graduate School of Medicine, Yokohama, Japan \\ ${ }^{2}$ Chugai Pharmaceutical Co., Ltd., Tokyo, Japan \\ ${ }^{3}$ National Center of Neurology and Psychiatry, Tokyo, Japan
}

Objective The aim of the present study was to perform a subgroup analysis of data from a phase II global, multi-center, randomized, double-blind, placebo-controlled study to evaluate the efficacy and safety of bitopertin, a glycine reuptake inhibitor that activates $\mathrm{N}$-methylD-aspartate receptors by increasing the concentration of glycine in the synaptic cleft, in Japanese and non-Japanese patients with schizophrenia and predominant negative symptoms.

Methods Patients with schizophrenia and predominant negative symptoms on one or two antipsychotic drugs, including atypical antipsychotic drugs (olanzapine, risperidone, quetiapine, aripiprazole, and paliperidone) as the primary treatment, received bitopertin (10, 30, or $60 \mathrm{mg} /$ day) or placebo once daily for 8 weeks as an add-on treatment. Efficacy was assessed using the Positive and Negative Syndrome Scale (PANSS) negative symptom factor score (NSFS).

Results The efficacy of bitopertin (10 mg and $30 \mathrm{mg}$ ) was similar between Japanese and non-Japanese patients. In the bitopertin 60 -mg group, no difference from the placebo group was observed in Japanese or non-Japanese patients. The response to placebo was lower in Japanese patients, and there was a trend towards a greater difference in the change in PANSS NSFS between the placebo group and the 10$\mathrm{mg}$ and 30-mg groups among Japanese patients. The safety profile of bitopertin was favorable in Japanese and non-Japanese patients.

Conclusion According to this subgroup analysis from a global phase II study of bitopertin, there was no difference in terms of efficacy and safety between Japanese and non-Japanese patients.

Psychiatry Investig 2017;14(1):63-73

Key Words Bitopertin, Japan, Negative symptoms, Schizophrenia, Placebo response.

\section{INTRODUCTION}

Patients with schizophrenia experience positive symptoms (e.g., hallucinations, delusions, catatonic symptoms, and incoherence of thought), negative symptoms (e.g., social withdrawal and blunted affect), and cognitive deficits. Reportedly, negative symptoms are closely related to functional impairments regarding the maintenance of personal care, performance of household chores, learning, ability to work or attend school, and interacting with others. ${ }^{1,2}$ Additionally, these

Received: November 26, 2015 Revised: May 5, 2016

Accepted: May 5, 2016 Available online: September 9, 2016

$\triangle$ Correspondence: Yoshio Hirayasu, MD, PhD

Department of Psychiatry, Yokohama City University Graduate School of Medicine, 3-9 Fukuura, Kanazawa-ku, Yokohama 236-0004, Japan

Tel: +81-45-787-2667, Fax: +81-45-783-2540

E-mail: hirayasu@yokohama-cu.ac.jp

(a) This is an Open Access article distributed under the terms of the Creative Commons Attribution Non-Commercial License (http://creativecommons.org/licenses/bync/3.0) which permits unrestricted non-commercial use, distribution, and reproduction in any medium, provided the original work is properly cited. symptoms seem to have a greater impact on social functioning than do positive symptoms. ${ }^{3}$

Conventional antipsychotic drugs do not provide sufficient improvement in negative symptoms; thus, effective treatments to satisfy this unmet need are anticipated. ${ }^{4,5}$ Because N-methyl-D-aspartate receptor (NMDAR) inhibitors, such as phencyclidine and ketamine, induce not only positive but also negative symptoms and cognitive deficits in healthy adults, ${ }^{6-9}$ NMDAR dysfunction has been proposed as a factor contributing to the negative symptoms of schizophrenia. ${ }^{10}$ Therefore, NMDA enhancers, such as glycine reuptake inhibitors (GRIs), may improve negative symptoms.

Bitopertin, a GRI that selectively inhibits a glycine transporter, GlyT1, activates NMDAR by increasing the concentration of glycine in the synaptic cleft. ${ }^{11}$ A proof-of-concept, global phase II study was conducted to investigate the clinical effect of bitopertin on negative symptoms in patients with schizophrenia. ${ }^{12}$ A significant improvement was observed in 


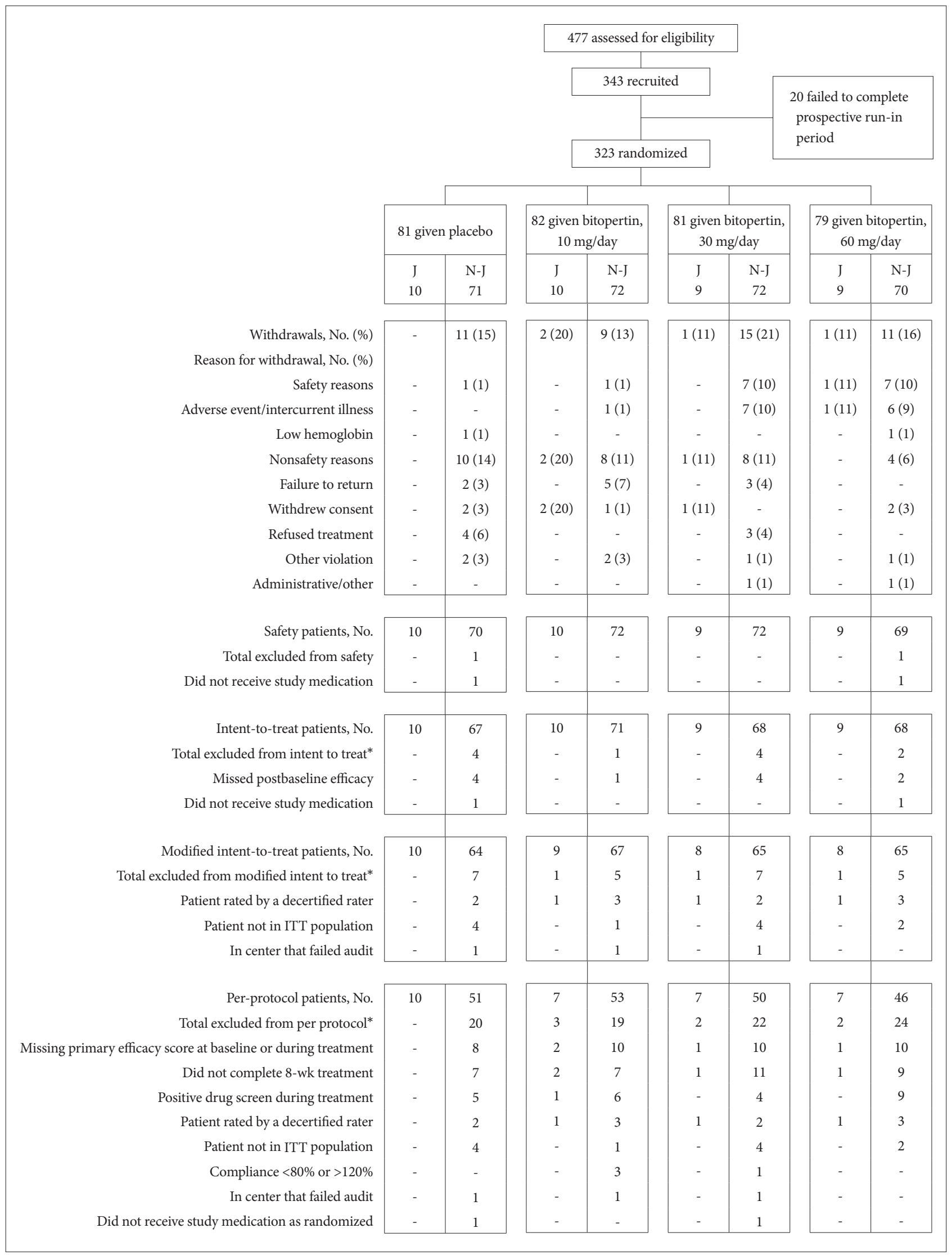

Figure 1. CONSORT diagram. *some patients were excluded for more than one reason. J: Japanese, N-J: non-Japanese. 
the 10-mg and 30-mg groups compared with the placebo group in the per-protocol population, and also a trend toward improvement was observed in the intent-to-treat (ITT) population.

To the best of our knowledge, this was the first global study in the field of psychiatry, led by Europe and the US and in-

Table 1. Analysis populations and baseline characteristics of the ITT population

\begin{tabular}{|c|c|c|c|c|c|c|c|c|}
\hline \multirow{4}{*}{ Characteristic } & \multirow{2}{*}{\multicolumn{2}{|c|}{ Placebo }} & \multicolumn{6}{|c|}{ Bitopertin } \\
\hline & & & \multicolumn{2}{|c|}{$10 \mathrm{mg} /$ day } & \multicolumn{2}{|c|}{$30 \mathrm{mg} /$ day } & \multicolumn{2}{|c|}{$60 \mathrm{mg} /$ day } \\
\hline & $\mathrm{J}$ & N-J & $\mathrm{J}$ & $\mathrm{N}-\mathrm{J}$ & $\mathrm{J}$ & N-J & $\mathrm{J}$ & N-J \\
\hline & $\mathrm{N}=10$ & $\mathrm{~N}=67$ & $\mathrm{~N}=10$ & $\mathrm{~N}=71$ & $\mathrm{~N}=9$ & $\mathrm{~N}=68$ & $\mathrm{~N}=9$ & $\mathrm{~N}=68$ \\
\hline \multicolumn{9}{|l|}{ Analysis population, $\mathrm{N}$} \\
\hline All randomized & 10 & 71 & 10 & 72 & 9 & 72 & 9 & 70 \\
\hline Safety ( $\geq 1$ dose) & 10 & 70 & 10 & 72 & 9 & 72 & 9 & 69 \\
\hline Intent to treat & 10 & 67 & 10 & 71 & 9 & 68 & 9 & 68 \\
\hline Modified intent to treat & 10 & 64 & 9 & 67 & 8 & 65 & 8 & 65 \\
\hline Per protocol & 10 & 51 & 7 & 53 & 7 & 50 & 7 & 46 \\
\hline \multicolumn{9}{|l|}{ Demographic } \\
\hline Male, N (\%) & $7(70)$ & $40(60)$ & $6(60)$ & $51(72)$ & $1(11)$ & $43(63)$ & $6(67)$ & $46(68)$ \\
\hline Age, mean (SD), years & $38(11)$ & $39(10)$ & $43(10)$ & $40(10)$ & $37(10)$ & $41(10)$ & $40(8)$ & $39(10)$ \\
\hline BMI, mean (SD), $\mathrm{kg} / \mathrm{m}^{2}$ & $25(3)$ & $29(6)$ & $24(4)$ & $29(5)$ & $27(6)$ & $29(6)$ & $24(4)$ & $28(6)$ \\
\hline \multicolumn{9}{|c|}{ Primary antipsychotic treatment, N (\%) } \\
\hline Aripiprazole & $2(20)$ & $6(9)$ & $2(20)$ & $7(10)$ & $3(33)$ & $7(10)$ & $2(22)$ & $6(9)$ \\
\hline Olanzapine & $2(20)$ & $19(28)$ & $2(20)$ & $21(30)$ & $1(11)$ & $20(29)$ & $2(22)$ & $20(29)$ \\
\hline Quetiapine & $1(10)$ & $9(13)$ & $2(20)$ & $10(14)$ & - & $10(15)$ & $1(11)$ & $10(15)$ \\
\hline Risperidone related & $5(50)$ & $32(48)$ & $4(40)$ & $31(44)$ & $5(56)$ & $28(41)$ & $4(44)$ & $31(46)$ \\
\hline Paliperidone* & - & $10(15)$ & - & $9(13)$ & - & $4(6)$ & - & $4(6)$ \\
\hline $\begin{array}{l}\text { Risperidone (incl. risperidone } \\
\text { long-acting injection*) }\end{array}$ & $5(50)$ & $22(33)$ & $4(40)$ & $22(31)$ & $5(56)$ & $24(35)$ & $4(44)$ & $27(40)$ \\
\hline \multicolumn{9}{|l|}{ Benzodiazepine treatment, $\mathrm{N}(\%)$} \\
\hline Total at least one treatment & $1(10)$ & $19(28)$ & $8(80)$ & $17(24)$ & $5(56)$ & $17(25)$ & $8(89)$ & $18(26)$ \\
\hline Clonazepam & $1(10)$ & $5(7)$ & $2(20)$ & $5(7)$ & $3(33)$ & $4(6)$ & - & $8(12)$ \\
\hline Lorazepam & $1(10)$ & $6(9)$ & - & $4(6)$ & $2(22)$ & $3(4)$ & $3(33)$ & $6(9)$ \\
\hline Alprazolam & - & $4(6)$ & $1(10)$ & $6(8)$ & $1(11)$ & $5(7)$ & - & $3(4)$ \\
\hline Diazepam & $1(10)$ & $2(3)$ & - & $2(3)$ & - & $2(3)$ & - & - \\
\hline Flunitrazepam & - & - & $5(50)$ & - & - & - & $4(44)$ & - \\
\hline Nitrazepam & - & - & $2(20)$ & - & $1(11)$ & - & - & - \\
\hline Quazepam & - & - & $2(20)$ & - & - & - & - & - \\
\hline Triazolam & - & - & $2(20)$ & - & - & - & - & - \\
\hline Brotizolam & $1(10)$ & - & - & - & - & - & $2(22)$ & - \\
\hline Bromazepam & - & - & - & - & $1(11)$ & $1(1)$ & $1(11)$ & $1(1)$ \\
\hline Etizolam & - & - & $1(10)$ & - & - & - & $1(11)$ & - \\
\hline Lormetazepam & $1(10)$ & - & - & - & - & - & $1(11)$ & - \\
\hline Ethyl loflazepate & - & - & - & - & - & - & $1(11)$ & - \\
\hline Flurazepam & - & - & - & - & - & - & $1(11)$ & - \\
\hline Prazepam & - & - & - & - & - & $1(1)$ & - & - \\
\hline Cinolazepam & - & $1(1)$ & - & - & - & - & - & - \\
\hline Estazolam & - & - & - & - & - & $1(1)$ & - & - \\
\hline Temazepam & - & $1(1)$ & - & - & - & - & - & - \\
\hline
\end{tabular}


Table 1. Analysis populations and baseline characteristics of the ITT population (continued)

\begin{tabular}{|c|c|c|c|c|c|c|c|c|}
\hline \multirow{4}{*}{ Characteristic } & \multirow{2}{*}{\multicolumn{2}{|c|}{ Placebo }} & \multicolumn{6}{|c|}{ Bitopertin } \\
\hline & & & \multicolumn{2}{|c|}{$10 \mathrm{mg} /$ day } & \multicolumn{2}{|c|}{$30 \mathrm{mg} /$ day } & \multicolumn{2}{|c|}{$60 \mathrm{mg} /$ day } \\
\hline & $\mathrm{J}$ & N-J & $\mathrm{J}$ & N-J & $\mathrm{J}$ & N-J & $\mathrm{J}$ & N-J \\
\hline & $\mathrm{N}=10$ & $\mathrm{~N}=67$ & $\mathrm{~N}=10$ & $\mathrm{~N}=71$ & $\mathrm{~N}=9$ & $\mathrm{~N}=68$ & $\mathrm{~N}=9$ & $\mathrm{~N}=68$ \\
\hline \multicolumn{9}{|l|}{$\begin{array}{l}\text { Baseline psychopathology and } \\
\text { functioning, mean (SE) }\end{array}$} \\
\hline \multicolumn{9}{|l|}{ PANSS } \\
\hline Total score & $83.4(2.7)$ & $78.2(1.0)$ & $79.4(3.7)$ & $79.4(1.1)$ & $83.4(3.3)$ & $79.5(1.3)$ & $83.4(2.6)$ & $77.9(1.0)$ \\
\hline Negative symptom factor score & $26.6(1.4)$ & $25.9(0.4)$ & $26.1(1.6)$ & $25.8(0.4)$ & $28.0(1.7)$ & $26.3(0.5)$ & $28.7(1.8)$ & $26.2(0.4)$ \\
\hline Positive symptom factor score & $19.2(0.8)$ & $17.4(0.5)$ & $18.5(1.2)$ & $17.7(0.4)$ & $19.7(0.9)$ & $17.6(0.5)$ & $18.9(0.9)$ & $17.1(0.4)$ \\
\hline $\begin{array}{l}\text { Disorganized thought/cognition } \\
\text { factor score }\end{array}$ & $20.8(1.3)$ & $20.6(0.4)$ & $19.7(1.2)$ & $21.5(0.4)$ & $20.1(1.6)$ & $20.8(0.4)$ & $19.7(1.6)$ & $20.4(0.3)$ \\
\hline $\begin{array}{l}\text { Uncontrolled hostility/excitement } \\
\text { factor score }\end{array}$ & $7.5(0.6)$ & $6.2(0.2)$ & $6.6(0.7)$ & $6.5(0.3)$ & $6.8(0.7)$ & $6.6(0.3)$ & $6.9(0.8)$ & $6.2(0.3)$ \\
\hline Anxiety/depression factor score & $9.3(0.5)$ & $8.1(0.3)$ & $8.5(0.9)$ & $8.0(0.3)$ & $8.9(1.1)$ & $8.2(0.4)$ & $9.3(0.7)$ & $8.0(0.3)$ \\
\hline CGI-S of negative symptoms & $4.9(0.2)$ & $4.4(0.1)$ & $4.8(0.3)$ & $4.4(0.1)$ & $4.9(0.4)$ & $4.4(0.1)$ & $4.7(0.3)$ & $4.4(0.1)$ \\
\hline PSP total score & $36.8(3.8)$ & $52.0(1.4)$ & $43.3(5.6)$ & $49.7(1.5)$ & $41.6(4.8)$ & $53.4(1.4)$ & $42.2(5.7)$ & $50.9(1.4)$ \\
\hline
\end{tabular}

*risperidone long-acting injection and paliperidone were not approved in Japan at the time of the study, but were used by some of the nonJapanese patients. BMI: body mass index, CGI-S: Clinical Global Impression of Severity, J: Japanese, N-J: non-Japanese, PANSS: Positive and Negative Syndrome Scale, PSP: Personal and Social Performance scale, SD: standard deviation, SE: standard error

volving Japan. Therefore, examining the impact of the differences between Japanese and non-Japanese patients based on demographic characteristics and social environment on the evaluation of the efficacy and safety of bitopertin may have clinical relevance. This manuscript is a report of a subgroup analysis comparing the efficacy and safety of bitopertin in 38 Japanese patients with those in non-Japanese patients.

\section{METHODS}

\section{Study design}

This is a subgroup analysis of data from a global, multicenter, randomized, double-blind, placebo-controlled study conducted between February 2008 and September 2009, including the participation of ten countries: Austria, Brazil, France, Germany, Hungary, Mexico, Poland, Russia, the US, and Japan. The patients were randomized to treatment in Japan and elsewhere separately. The detailed methods were previously published. ${ }^{12}$

\section{Study subjects}

According to the recommendations by the National Institute of Mental Health-Measurement and Treatment Research to Improve Cognition in Schizophrenia consensus statement on negative symptoms, ${ }^{13,14}$ schizophrenic outpatients with chronic stable positive symptoms and prominent negative symptoms were recruited, and patients with uncontrolled extrapyramidal symptoms and depressive symptoms were excluded from the present study. All patients gave informed consent to participate in the study and their anonymity was preserved.

\section{Drugs}

Bitopertin (10, 30, or $60 \mathrm{mg} /$ day) or placebo was administered once daily, in addition to the primary treatment (one or two antipsychotic drugs, including atypical antipsychotic drugs such as olanzapine, risperidone, quetiapine, aripiprazole, and paliperidone).

\section{Endpoints}

The primary endpoint was the mean change from baseline in the negative symptom factor score (NSFS) of the Positive and Negative Syndrome Scale (PANSS). ${ }^{15}$ The secondary endpoints were the PANSS NSFS response rate ( $\geq 20 \%$ change), other PANSS factor scores, PANSS total score, PANSS symptom scores, Clinical Global Impression-Improvement (CGI-I) of negative symptoms, ${ }^{16}$ functioning on the Personal and Social Performance scale (PSP), ${ }^{17}$ and safety.

\section{Statistical methods}

A mixed-model repeated-measure analysis (MMRM) was used for variables with repeated scheduled measurements. The MMRM model included fixed-effect terms for treatment group, visit week (categorical and nested within patient), baseline score, treatment-by-visit interaction, and the inter- 
action between baseline score and visit week. Statistical methods are described in detail in the original paper. ${ }^{12}$ Data from Japanese and non-Japanese sites for key efficacy and safety variables were compared in the ITT population. This comparison should be interpreted with caution because of the small number of patients from Japanese sites. Statistical significance was not evaluated. In a post-hoc analysis, the correlations between the PSP total score and the score for each PANSS symptom factor at baseline were examined.

\section{RESULTS}

In the original study, 323 of 477 screened patients were randomly assigned to receive placebo or bitopertin (10, 30 or 60 $\mathrm{mg} /$ day). Results have been published and other details can be found in the original paper. ${ }^{12}$

\section{Patient demographics and baseline characteristics}

Of the 323 patients randomly assigned to treatment, 38 were Japanese: of these, all 38 were included in the ITT population and 34 patients completed the study (Figure 1). Regarding pri- mary antipsychotic treatment, the most commonly used drug was risperidone (47\%), followed by aripiprazole (24\%) and olanzapine (18\%) in Japanese patients. In non-Japanese patients, risperidone-related products were the most common [risperidone, paliperidone, and risperidone long-acting injection, (45\%)], followed by olanzapine (29\%), quetiapine (14\%), and aripiprazole (9\%). The proportion of Japanese patients receiving benzodiazepine concomitantly was higher than that of non-Japanese patients (58\% versus 26\%, respectively) (Table 1).

\section{Efficacy}

At week 8 from baseline, an effect of bitopertin $10 \mathrm{mg}$ and $30 \mathrm{mg}$ on negative symptoms was observed in both Japanese (-4.7 and -6.4 in the 10-mg and 30-mg groups, respectively) and non-Japanese patients (-6.7 and -6.4 , respectively) on the basis of a greater difference in the change in PANSS NSFS (Table 2). The same trend was observed for PANSS NSFS response rate in both Japanese and non-Japanese patients (Table 2, Figure 2). There was no difference in the change from baseline at week 8 in PANSS NSFS between the bitopertin $60-\mathrm{mg}$ group and the placebo group in Japanese $(-2.5$ and

Table 2. Primary and secondary endpoints (ITT population)

\begin{tabular}{|c|c|c|c|c|c|c|c|c|}
\hline \multirow{3}{*}{ End points } & \multirow{2}{*}{\multicolumn{2}{|c|}{ Placebo }} & \multicolumn{6}{|c|}{ Bitopertin } \\
\hline & & & \multicolumn{2}{|c|}{$10 \mathrm{mg} /$ day } & \multicolumn{2}{|c|}{$30 \mathrm{mg} /$ day } & \multicolumn{2}{|c|}{$60 \mathrm{mg} /$ day } \\
\hline & $\mathrm{J}$ & $\mathrm{N}-\mathrm{J}$ & $\mathrm{J}$ & $\mathrm{N}-\mathrm{J}$ & $\mathrm{J}$ & $\mathrm{N}-\mathrm{J}$ & $\mathrm{J}$ & $\mathrm{N}-\mathrm{J}$ \\
\hline PANSS negative symptom factor score $(\mathrm{N})$ & $(10)$ & $(67)$ & $(10)$ & $(71)$ & (9) & $(68)$ & (9) & $(68)$ \\
\hline Change from baseline at wk 8 (SE) & $-2.5(1.2)$ & $-5.5(0.6)$ & $-4.7(1.3)$ & $-6.7(0.5)$ & $-6.4(1.4)$ & $-6.4(0.6)$ & $-3.2(1.3)$ & $-5.3(0.6)$ \\
\hline $\begin{array}{l}\text { Negative symptom response* } \\
\text { ( } \geq 20 \% \text { improvement of NSFS from } \\
\text { baseline) }(\mathrm{N})\end{array}$ & $(10)$ & $(59)$ & $(8)$ & $(63)$ & $(8)$ & $(58)$ & $(8)$ & $(58)$ \\
\hline Patients meeting response criterion, $\%$ & 30 & 47 & 63 & 65 & 63 & 59 & 0 & 52 \\
\hline CGI-I negative symptoms, $\%(\mathrm{~N})^{*}$ & $(10)$ & $(59)$ & (8) & $(63)$ & (8) & $(58)$ & (8) & $(58)$ \\
\hline Very much improved & 10 & 2 & 0 & 3 & 0 & 9 & 0 & 2 \\
\hline Much improved & 10 & 19 & 50 & 32 & 50 & 31 & 0 & 31 \\
\hline Minimally improved & 30 & 47 & 25 & 48 & 13 & 38 & 63 & 29 \\
\hline No change & 50 & 32 & 25 & 17 & 38 & 21 & 25 & 38 \\
\hline Minimally worse & 0 & 0 & 0 & 0 & 0 & 2 & 13 & 0 \\
\hline PSP total score $(\mathrm{N})^{*}$ & $(10)$ & (59) & (8) & $(63)$ & $(8)$ & (58) & $(8)$ & $(58)$ \\
\hline Change from baseline at wk 8 (SE) & $5.7(2.6)$ & $6.5(1.2)$ & $10.3(2.9)$ & $8.6(1.1)$ & $5.8(2.9)$ & $7.8(1.2)$ & $3.4(2.9)$ & $7.8(1.2)$ \\
\hline PANSS positive symptom factor score $(\mathrm{N})$ & $(10)$ & $(67)$ & $(10)$ & $(71)$ & (9) & $(68)$ & (9) & $(68)$ \\
\hline Change from baseline at wk 8 (SE) & $0.1(0.9)$ & $-1.4(0.4)$ & $-0.5(1.0)$ & $-1.9(0.4)$ & $-2.3(1.0)$ & $-1.0(0.4)$ & $-1.5(1.0)$ & $-1.3(0.4)$ \\
\hline $\begin{array}{l}\text { PANSS disorganized thought/cognition } \\
\text { factor score }(\mathrm{N})\end{array}$ & $(10)$ & $(67)$ & $(10)$ & $(71)$ & (9) & $(68)$ & (9) & $(68)$ \\
\hline Change from baseline at wk 8 (SE) & $-1.2(0.9)$ & $-3.5(0.4)$ & $-1.4(0.9)$ & $-4.0(0.4)$ & $-3.3(1.0)$ & $-4.0(0.4)$ & $-1.7(1.0)$ & $-3.4(0.4)$ \\
\hline PANSS total score $(\mathrm{N})$ & $(10)$ & $(67)$ & $(10)$ & $(71)$ & (9) & $(68)$ & (9) & $(68)$ \\
\hline Change from baseline at wk 8 (SE) & $-3.8(3.2)$ & $-11.9(1.5)$ & $-7.3(3.4)$ & $-13.9(1.4)$ & $-14.0(3.6)$ & $-13.3(1.5)$ & $-7.7(3.5)$ & $-11.0(1.5)$ \\
\hline
\end{tabular}

*observed case at week 8. CGI-I: Clinical Global Impression of Improvement, J: Japanese, N-J: non-Japanese, PANSS: Positive and Negative Syndrome Scale, NSFS: negative symptom factor score, PSP: Personal and Social Performance scale, SE: standard error, wk: week 

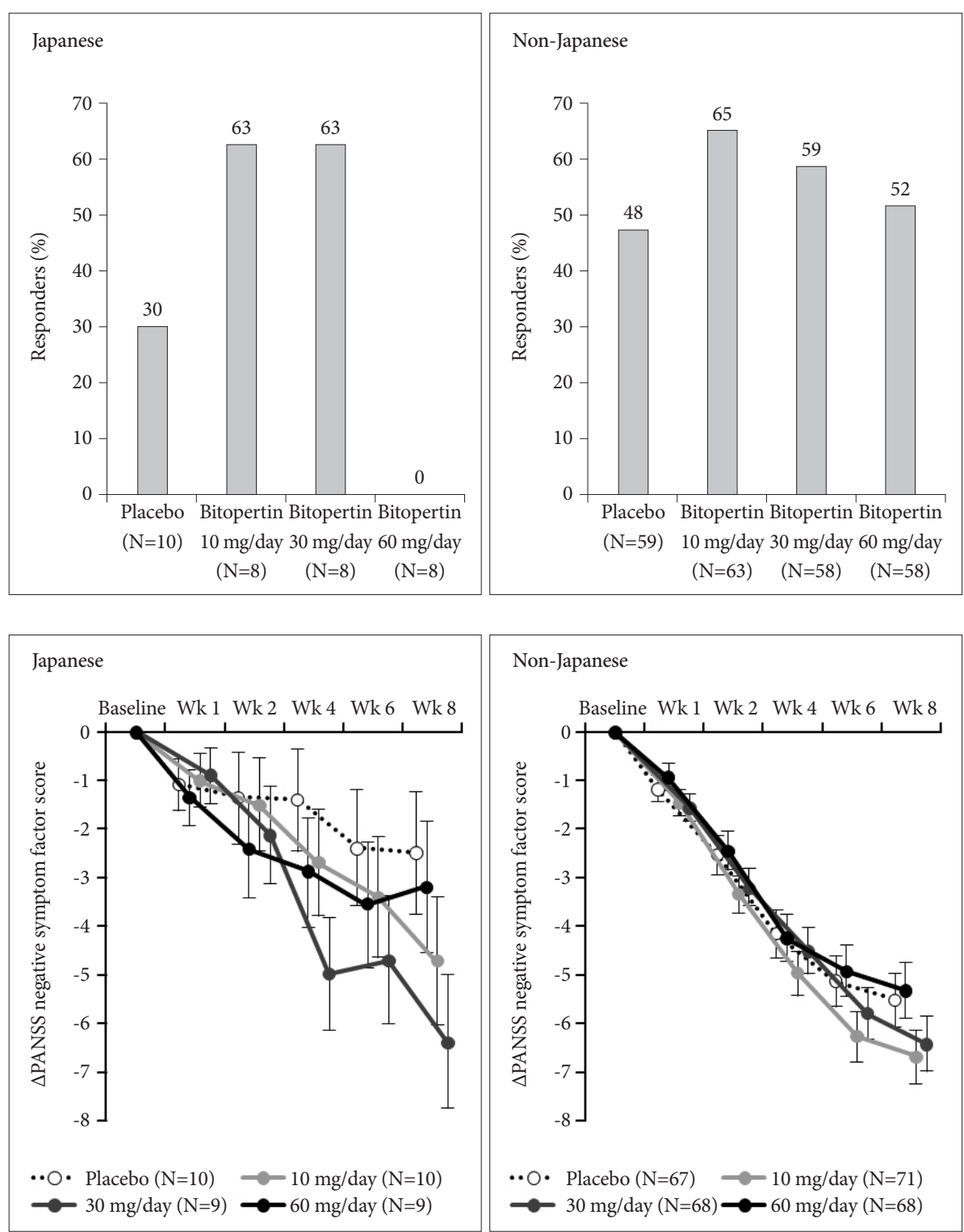

Non-Japanese

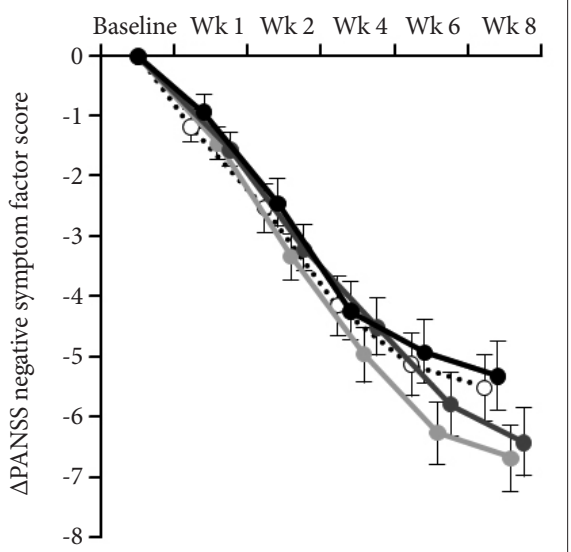

••○・ Placebo $(\mathrm{N}=67) \longrightarrow 10 \mathrm{mg} / \mathrm{day}(\mathrm{N}=71)$ $30 \mathrm{mg} /$ day $(\mathrm{N}=68) \longrightarrow 60 \mathrm{mg} /$ day $(\mathrm{N}=68)$
Figure 2. Positive and Negative Syndrome Scale negative symptom factor score response rates at week 8 (intentto-treat population).

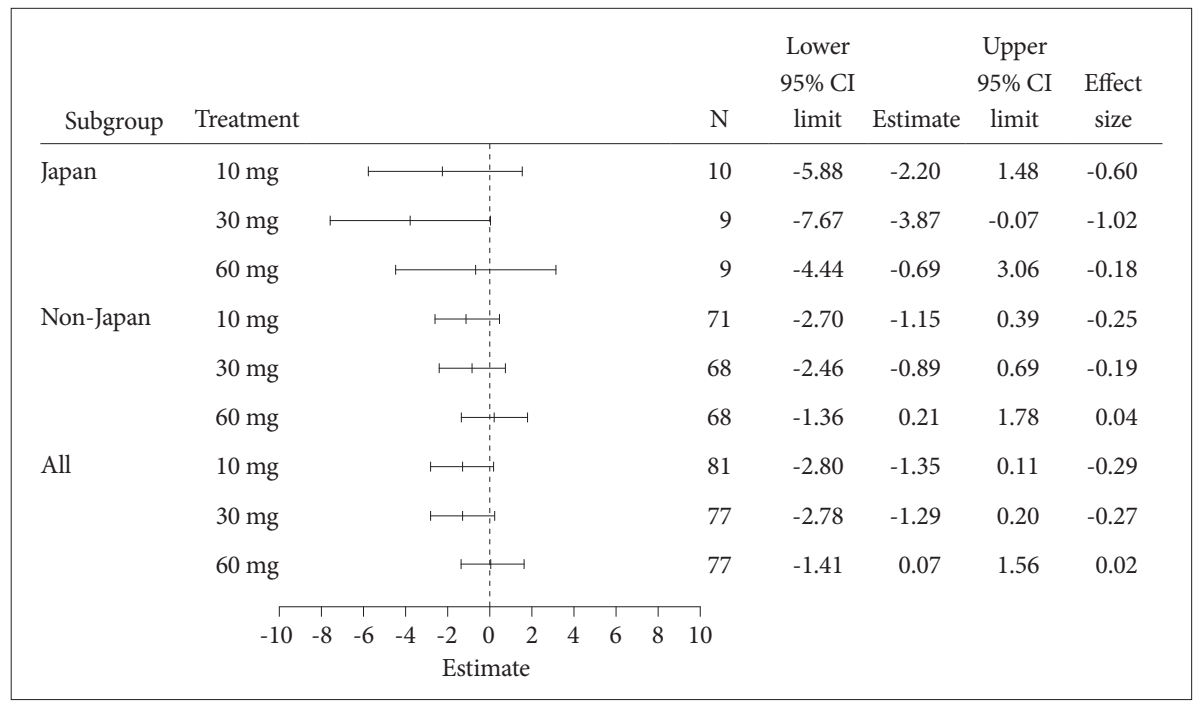

Figure 3. Change in Positive and Negative Syndrome Scale (PANSS) negative symptom factor score from baseline [intent-to-treat population; mean (standard error)].
Figure 4. Differences from placebo and effect sizes of Positive and Negative Syndrome Scale negative symptom factor score change from baseline at week 8 (intent-to-treat population) based on mixed-model repeated-measure analysis. 
-3.2 in the placebo and 60-mg groups, respectively) or nonJapanese patients (-5.5 and -5.3 in the placebo and $60-\mathrm{mg}$ groups, respectively), which was in congruence with the re- sults of the original study (Table 2). In Japanese patients, the response to placebo was lower than in non-Japanese patients, and there was a trend toward a greater difference in the change
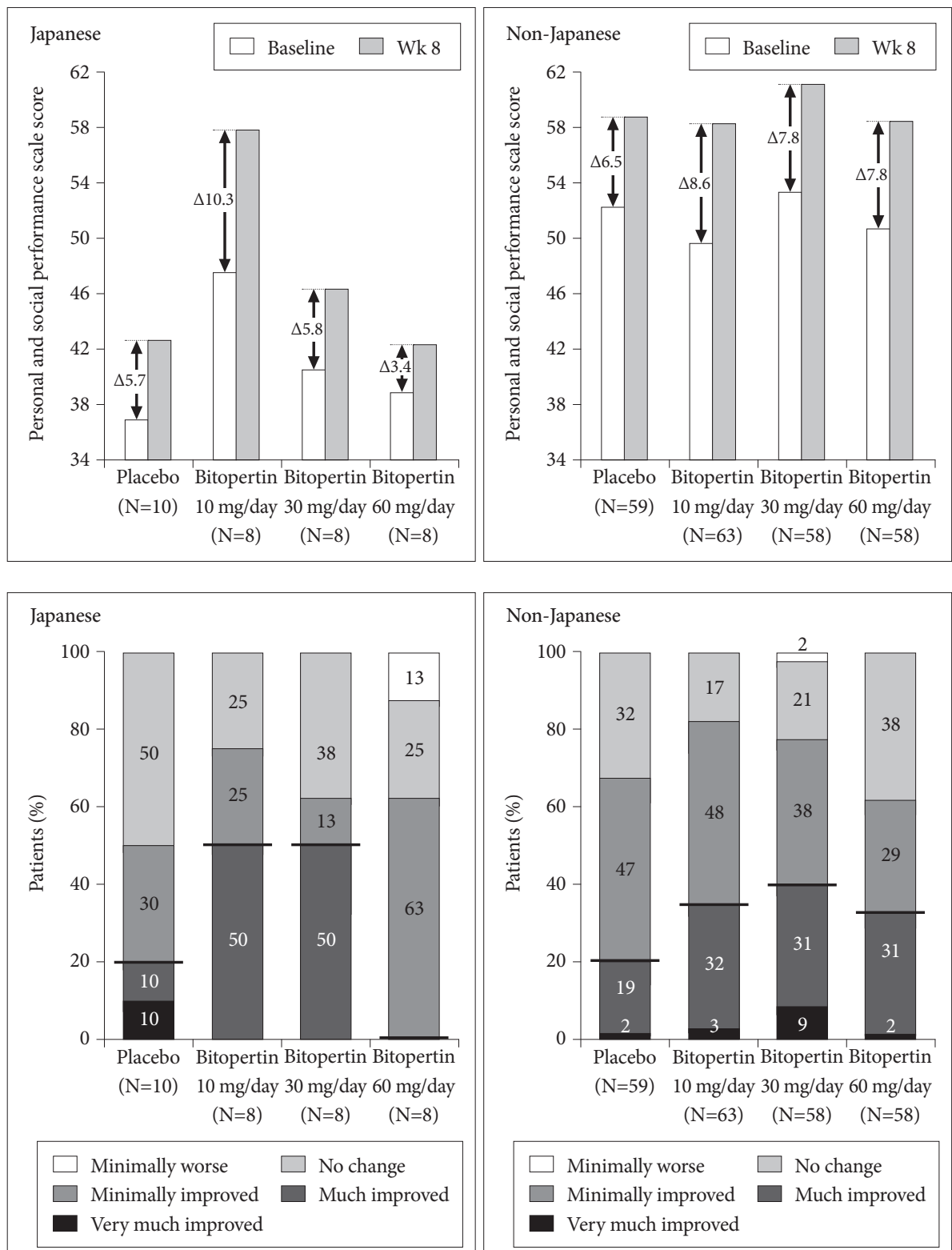

Non-Japanese

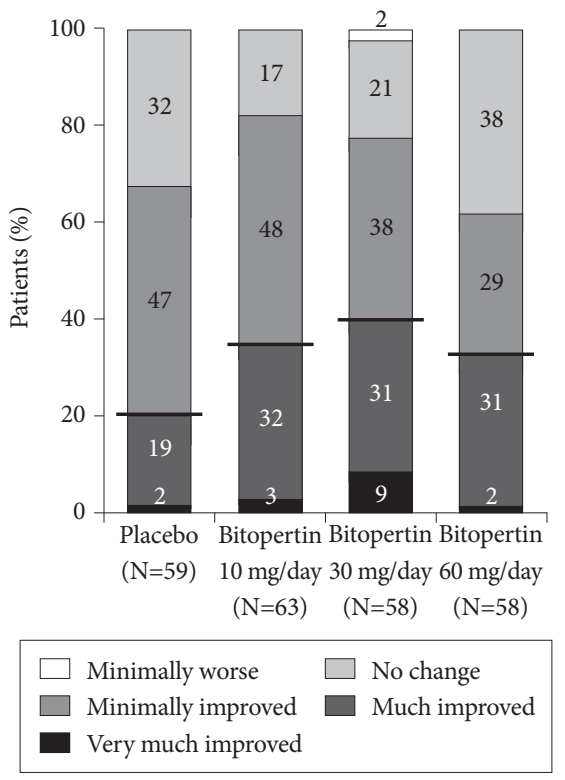

Figure 5. Change in Personal and Social Performance Scale score from baseline at week 8 (intent-to-treat population). Changes were compared using analysis of covariance, as described in the original paper. ${ }^{12}$

Table 3. Correlation between personal and social performance total score and PANSS factor scores at baseline (ITT population)

\begin{tabular}{|c|c|c|c|c|c|c|}
\hline \multirow{2}{*}{$\begin{array}{l}\text { Positive and Negative Syndrome } \\
\text { Scale factor scores }\end{array}$} & \multicolumn{2}{|l|}{ Total } & \multicolumn{2}{|c|}{ Japanese } & \multicolumn{2}{|c|}{ Non-Japanese } \\
\hline & $\begin{array}{l}\text { Correlation with } \\
\text { PSP total score }\end{array}$ & $\mathrm{R}^{2}$ & $\begin{array}{l}\text { Correlation with } \\
\text { PSP total score }\end{array}$ & $\mathrm{R}^{2}$ & $\begin{array}{l}\text { Correlation with } \\
\text { PSP total score }\end{array}$ & $\mathrm{R}^{2}$ \\
\hline Anxiety/depression & -0.0174 & 0.0003 & -0.0763 & 0.0058 & 0.0285 & 0.0008 \\
\hline Disorganized thought/cognition & -0.1520 & 0.0231 & -0.1440 & 0.0207 & -0.1866 & 0.0348 \\
\hline Uncontrolled hostility/excitement & -0.1194 & 0.0143 & -0.0795 & 0.0063 & -0.1036 & 0.0107 \\
\hline Negative symptom & -0.3725 & 0.1387 & -0.4089 & 0.1672 & -0.3473 & 0.1206 \\
\hline Positive symptom & -0.1373 & 0.0189 & -0.2174 & 0.0473 & -0.0887 & 0.0079 \\
\hline
\end{tabular}

Data are shown as correlation coefficients (R) and $\mathrm{R}^{2}$. PSP: personal and social performance 
in PANSS factor scores between the placebo group and the 10-mg and 30-mg groups, in particular for the 30-mg group (Figure 3, Table 2). In the 10-mg and 30-mg groups, the effect sizes (the mean difference divided by the common standard deviation) for the change in NSFS were -0.60 and -1.02 , respectively, among Japanese patients, and -0.25 and -0.19 , respectively, among non-Japanese patients (Figure 4).

The PSP score improved at week 8 in both Japanese and non-Japanese patients, while baseline PSP scores were generally lower in Japanese than non-Japanese patients (Figure 5, Table 2).

The response rate ("Very much improved" and "Much im-

Table 4. Number of patients with at least one AE and SAE (safety population)

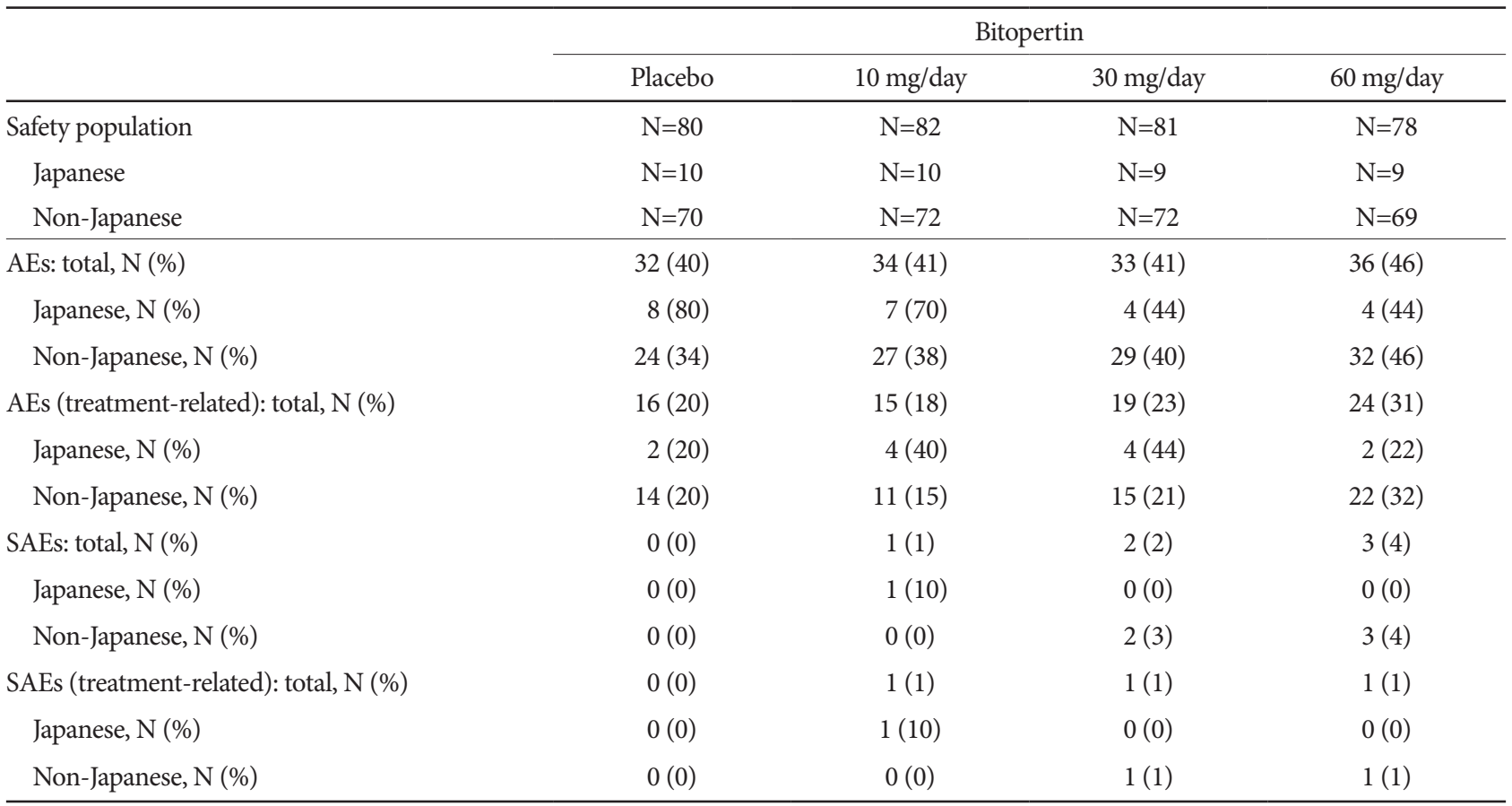

AEs: adverse events, SAEs: serious adverse events, $\mathrm{N}$ : number of patients

Table 5. Adverse events occurring at an incidence of $5 \%$ or more in the total population (safety population)

\begin{tabular}{|c|c|c|c|c|}
\hline & \multicolumn{4}{|c|}{ Bitopertin } \\
\hline & Placebo & $10 \mathrm{mg} /$ day & $30 \mathrm{mg} /$ day & $60 \mathrm{mg} /$ day \\
\hline Safety population & $\mathrm{N}=80$ & $\mathrm{~N}=82$ & $\mathrm{~N}=81$ & $\mathrm{~N}=78$ \\
\hline Japanese & $\mathrm{N}=10$ & $\mathrm{~N}=10$ & $\mathrm{~N}=9$ & $\mathrm{~N}=9$ \\
\hline Non-Japanese & $\mathrm{N}=70$ & $\mathrm{~N}=72$ & $\mathrm{~N}=72$ & $\mathrm{~N}=69$ \\
\hline Somnolence: total, N (\%) & $2(3)$ & $6(7)$ & $4(5)$ & $8(10)$ \\
\hline Japanese, N (\%) & $0(0)$ & $2(20)$ & $1(11)$ & $2(22)$ \\
\hline Non-Japanese, N (\%) & $2(3)$ & $4(6)$ & $3(4)$ & $6(9)$ \\
\hline Dizziness: total, N (\%) & $2(3)$ & $1(1)$ & $3(4)$ & $9(12)$ \\
\hline Japanese, N (\%) & $2(20)$ & $1(10)$ & $2(22)$ & $1(11)$ \\
\hline Non-Japanese, N (\%) & $0(0)$ & $0(0)$ & $1(1)$ & $8(12)$ \\
\hline Headache: total, N (\%) & $1(1)$ & $2(2)$ & $2(2)$ & $7(9)$ \\
\hline Japanese, N (\%) & $0(0)$ & $0(0)$ & $1(11)$ & $1(11)$ \\
\hline Non-Japanese, N (\%) & $1(1)$ & $2(3)$ & $1(1)$ & $6(9)$ \\
\hline Nasopharyngitis: total, N (\%) & $6(8)$ & $4(5)$ & $0(0)$ & $2(3)$ \\
\hline Japanese, N (\%) & $3(30)$ & $2(20)$ & $0(0)$ & $1(11)$ \\
\hline Non-Japanese, N (\%) & $3(4)$ & $2(3)$ & $0(0)$ & $1(1)$ \\
\hline
\end{tabular}

$\mathrm{N}$ : number of patients 
proved") in CGI-I negative symptoms score at week 8 (Figure 6 , Table 2) was greater in the $10-\mathrm{mg}$ and 30 -mg groups than in the placebo group, in Japanese and non-Japanese patients.

In a post-hoc analysis, the correlations between the PSP total score and the score for each PANSS symptom factor at baseline were examined. The strongest correlations were between the PSP score and the PANSS negative symptom factor score, in both Japanese and non-Japanese patient populations (Japanese: correlation coefficient=-0.41; non-Japanese: correlation coefficient $=-0.35$ ) (Table 3 ).

\section{Safety}

There were no major differences in safety profiles between Japanese and non-Japanese patients (Table 4 and 5). The most common adverse event in Japanese patients was "dizziness" and "Nasopharyngitis". The incidence rates of "somnolence," "dizziness," and "headache" were higher in the 60-mg group in non-Japanese patients, but this trend was not observed in Japanese patients (Table 5). "Anxiety" in one patient in the 10-mg group was the only serious adverse event observed among Japanese patients (data not shown).

Dose-dependent changes in the mean blood hemoglobin concentration were observed in Japanese and non-Japanese patients. Decrease of $>2.0 \mathrm{~g} / \mathrm{dL}$ in hemoglobin was seen in 4 to $22 \%$ of the non-Japanese patients; however, only one Japanese patient was reported in the 60-mg group (Table 6). Otherwise, no clinically significant changes were observed in vital signs, electrocardiograms, or extrapyramidal symptoms (BAS, SAS, and AIMS) in the safety analysis population. No other particular concerns were observed in Japanese patients.

\section{DISCUSSION}

This clinical trial was a proof-of-concept study designed to assess the efficacy of bitopertin on negative symptoms of schizophrenia in clinical settings. In this study conducted in ten countries, including Japan, a significant improvement in PANSS NSFS, the primary endpoint, was observed in the per-protocol population. The safety profile of bitopertin was also confirmed in patients with schizophrenia. Furthermore, in this study, a similar profile was observed in the Japanese patients treated with bitopertin 10 and $30 \mathrm{mg}$; the $60-\mathrm{mg}$ dose was essentially ineffective for improving PANSS NSFS.

Although baseline PSP scores were lower among Japanese patients, there were no differences between Japanese and nonJapanese patients in terms of demographic characteristics and baseline symptom scores on the PANSS and CGI. Social acceptance of patients with schizophrenia has been reported to be lower in Japan than in the US and Australia. ${ }^{18,19}$ According to the PSP, which assesses the severity of impairment of personal and social functioning based on information from caregivers, prejudice toward patients with schizophrenia may be a contributing factor to the lower rating in Japanese patients among those with similar severity of symptoms. Examination of differences between Japanese and non-Japanese patients in each PSP domain revealed that the personal and social functioning tended to be rated lower on average in the Japanese population in all domains of "Socially useful activities," "Personal and social relationships," "Self-care," and "Disturbing and aggressive behaviors" (data not shown). Despite the difference in the baseline, changes in PSP were similar between Japanese and non-Japanese patients.

Although differences were observed in the type of antipsychotic drugs and concomitant use rate of benzodiazepine between Japanese and non-Japanese patients, these did not significantly affect the efficacy and safety evaluations. Risperidonerelated products were found to be the most commonly used concomitant drugs in both Japanese and non-Japanese patients. Olanzapine and aripiprazole were also commonly used in both Japanese and non-Japanese patients. However, olanzapine was much more commonly used among non-Japanese patients ( $29 \%$ vs. $18 \%$ ), and aripiprazole was much more commonly used among Japanese patients (24\% vs. $9 \%$ ). The World Federation of Societies of Biological Psychiatry Guidelines for Treatment of Schizophrenia recommends olanzapine and amisulpride for the treatment of primary negative symptoms. ${ }^{20} \mathrm{~A}$

Table 6. Number of patients with a decrease in hemoglobin (>2.0 g/dL) from baseline (safety population)

\begin{tabular}{|c|c|c|c|c|}
\hline & \multicolumn{4}{|c|}{ Bitopertin } \\
\hline & Placebo & $10 \mathrm{mg} /$ day & $30 \mathrm{mg} /$ day & $60 \mathrm{mg} /$ day \\
\hline Safety population & $\mathrm{N}=80$ & $\mathrm{~N}=82$ & $\mathrm{~N}=81$ & $\mathrm{~N}=78$ \\
\hline Japanese & $\mathrm{N}=10$ & $\mathrm{~N}=10$ & $\mathrm{~N}=9$ & $\mathrm{~N}=9$ \\
\hline Non-Japanese & $\mathrm{N}=70$ & $\mathrm{~N}=72$ & $\mathrm{~N}=72$ & $\mathrm{~N}=69$ \\
\hline Hemoglobin decreased (>2.0 g/dL): total, $\mathrm{N}(\%)$ & $3(4)$ & $4(5)$ & $8(10)$ & $16(21)$ \\
\hline Japanese, N (\%) & $0(0)$ & $0(0)$ & $0(0)$ & $1(11)$ \\
\hline Non-Japanese, N (\%) & $3(4)$ & $4(6)$ & $8(11)$ & $15(22)$ \\
\hline
\end{tabular}

$\mathrm{N}$ : number of patients 
meta-analysis conducted by Leucht et al. ${ }^{21}$ has shown that aripiprazole is the best tolerated and has the least sedative effects among the atypical antipsychotics allowed as concomitant baseline medications in the present study (risperidone, olanzapine, quetiapine, and aripiprazole). The common use of aripiprazole in the Japanese patient population may be a reflection of prescription practices that put emphasis on the tolerability in chronic patients rather than the treatment of primary negative symptoms. The difference between Japanese and non-Japanese patients in the proportion of patients receiving a benzodiazepine concomitantly in the present study appears to reflect the general trend of prescription use for patients with schizophrenia in Japan.

In the present study, the placebo response was lower in Japanese patients than in non-Japanese patients. Similar trends were observed in clinical trials on another antipsychotic drug for schizophrenia. ${ }^{22-25}$ In the original paper, the authors suggested the improvement observed in the placebo group may be attributed to the intense interaction and intimate communication between the patients and the study staff in a clinical trial setting. ${ }^{12}$ In Japan, patients enrolled in clinical studies are mostly those cared for by clinical investigators. Therefore, there are no major differences between the routine clinical practice and that during participation in a clinical study. This may explain the small placebo response in this study.

A meta-analysis of placebo-controlled studies of antipsychotic drugs conducted from 1970 onwards found a gradual increase in placebo response in the past $2-30$ years. ${ }^{26}$ The authors suggested this increase could be explained by an increase in the number of study sites per study and a decrease in the percentage of academic sites participating. In the editorial accompanying the meta-analysis, ${ }^{27}$ Leucht et al. discuss that nonacademic sites are more motivated by financial incentives; thus, they aim to enroll as many patients as possible. This trend will create greater variation in study results, thereby decreasing differences in efficacy between the active drug and placebo. There were 13 facilities participating in this study from Japan, and most of them are academic sites (nine university hospitals and three national hospitals). This participation proclivity may have contributed to the difference in placebo response between Japanese and non-Japanese patients.

To minimize the risk of differences in technical expertise and to increase inter-rater reliability, raters in this study received standardized training. Absolute differences were observed in all treatment arms, which showed that appropriate evaluation was implemented. Additionally, cultural, habitual, and environmental factors were considered possible explanations for the placebo response rate difference. Although these factors cannot be ruled out, the mean change in Japanese patients was not lower than that in non-Japanese patients in all bitopertin groups, while the mean change in the PANSS positive symptom factor score in the 30-mg group was actually lower in non-Japanese than in Japanese patients.

There were no major differences in the safety profile between Japanese and non-Japanese patients, and bitopertin was generally well tolerated. No adverse events were reported with higher incidences among Japanese patients. No abnormal laboratory changes characteristic of Japanese patients were reported. These results show that bitopertin is tolerated in Japanese and non-Japanese patients with schizophrenia and predominant negative symptoms.

Glycine is essential for heme synthesis in erythroid progenitors and reticulocytes, ${ }^{28}$ and is taken up by GlyT1, into the cells. ${ }^{29}$ Therefore, there is concern that bitopertin, which is a GlyT1 inhibitor, may decrease hemoglobin. As expected, a dose-dependent decrease was observed. Although the number of patients with a decrease of $>2.0 \mathrm{~g} / \mathrm{dL}$ in blood hemoglobin concentration increased in a dose-dependent manner among non-Japanese patients, this decrease was observed in only one Japanese patient in the group receiving the highest dosage. However, there was no difference in the mean blood hemoglobin change between Japanese and non-Japanese patients.

Concordantly with the original study, ${ }^{12}$ this subgroup analysis for Japanese patients confirmed the efficacy of bitopertin on negative symptoms as an add-on to the existing antipsychotic therapy, and its favorable safety profile in patients with schizophrenia, during an 8-week treatment. When comparing Japanese and non-Japanese patient populations, the efficacy and safety profiles of bitopertin were generally similar in the 10-mg and 30-mg groups. Although there were differences between Japanese and non-Japanese patients in the type and frequency of antipsychotic drugs and concomitant benzodiazepine use, none of these differences affected the efficacy and safety evaluations significantly.

\section{Acknowledgments}

The authors thank Dr Jennifer Dreyer and Dr Keyra Martinez Dunn for providing medical writing support, which was funded by Chugai Pharmaceutical. Co., Ltd. The authors would also like to thank F. Hoffmann-La Roche for conducting the statistical analyses. The authors are grateful to Dr. Daniel Umbricht and Dr. Dragana Bugarski-Kirola for their critical review of the paper. This study was sponsored by F. Hoffman-La Roche Ltd and Chugai Pharmaceutical Co., Ltd.

We thank the investigators of the phase 2 study for recruiting and assessing patients: Csaba Almasi, Aleksander Araszkiewicz, Alla Avedisova, Istvæn Bitter, Przemyslaw Bogacki, Rodrigo Bressan, David Brown, Miranda Chakos, Læszl Csekey, Marek Cwiakala, Daniel Dassa, Natalia Dobrovolskaya, Helio Elkis, Tetsuro Enomoto, Donald Garcia, Hamilton Grabowski, Andrey Gribanov, Jun Ishigooka, Nakao Iwata, Mieczyslaw Janiszewski, Lala Kasimova, Hiroaki Kawasaki, Mary Knesevich, Sændor Koffler, Alex Kopelowicz, Alexsander Kotsubinsky, Jelena Kunovac, Tamas Kurimay, Toshihide Kuroki, Ichiro Kusumi, Mark Lerman, Andreas Mahler, Margarita Morozova, Joaquim Mota Neto, Tadashi Murakami, Judit Nagy, Henry Nasrallah, Nikolay Neznanov, Claus Normann, Mark Novitsky, Yohtaro Numachi, Toshinari Odawara, Tetsuro Ohmori, Irismar Reis de Oliveira, 
Alfonso Ontiveros, György Ostorharics-Horvæth, Hiroki Ozawa, Høctor Pinedo, Philippe Raymondet, Robert Reisenberg, Sandra Ruschel, Margot Schmitz, Gunther Schumann, Kazumasa Shiozaki, Rajinder Shiwach, George Simpson, Joachim Springub, Klaus Steinwachs, Jaroslaw Strzelec, Louise Thurman, Gabor Vincze, David Walling, Ryszard Wardenski, Kauser Yakhin, Reiji Yoshimura, and Marcel Zins-Ritter.

\section{Conflicts of Interest}

YH has served as a clinical trial advisor for Otsuka Pharmaceutical Co., Ltd. and Chugai Pharmaceutical Co., Ltd.; has served on an advisory board for Mochida Pharmaceutical Co., Ltd., Mitsubishi Tanabe Pharma Corporation, Eli Lilly Japan K.K., Chugai Pharmaceutical Co., Ltd., and Janssen Pharmaceutical K.K.; has received research grant from Otsuka Pharmaceutical Co., Ltd., Mochida Pharmaceutical Co., Ltd., Yoshitomiyakuhin Corporation, Janssen Pharmaceutical K.K., Shionogi \& Co., Ltd., GlaxoSmithKline K.K., Pfizer Japan Inc., Sanofi K.K., Astellas Pharma Inc., and Sumitomo Dainippon Pharma Co., Ltd.; has received a lecture honorarium from Otsuka Pharmaceutical Co., Ltd., Mochida Pharmaceutical Co., Ltd., Meiji Seika Pharma Co., Ltd., Eli Lilly Japan K.K., Sumitomo Dainippon Pharma Co., Ltd., GlaxoSmithKline K.K., Astellas Pharma Inc., MSD K.K., Asahi Kasei Pharma Corporation, Ono Pharmaceutical Co., Ltd., Yoshitomiyakuhin Corporation, and Eisai Co., Ltd.

TH has served on an advisory board for and/or received a lecture honorarium from Asahi Kasei Pharma Corporation, Astellas Pharma Inc., AbbVie GK, MSD K.K., Otsuka Pharmaceutical Co., Ltd., GlaxoSmithKline K.K., Shionogi \& Co., Ltd., Sumitomo Dainippon Pharma Co., Ltd., Chugai Pharmaceutical Co., Ltd., Eli Lilly Japan K.K., Pfizer Japan Inc., Meiji Seika Pharma Co., Ltd., Mochida Pharmaceutical Co., Ltd., Janssen Pharmaceutical K.K., Kyowa Hakko Kirin Co., Ltd., Kyowa Pharmaceutical Industry Co., Ltd., Mitsubishi Tanabe Pharma Corporation, and Yoshitomiyakuhin Corporation. SS, NS, and MN are employees of Chugai Pharmaceutical Co., Ltd.

\section{REFERENCES}

1. Buchanan RW, Gold JM. Negative symptoms: diagnosis, treatment and prognosis. Int Clin Psychopharmacol 1996;11(Suppl 2):3-11.

2. Andreasen NC. Negative symptoms in schizophrenia. Definition and reliability. Arch Gen Psychiatry 1982;39:784-788.

3. Rabinowitz J, Levine SZ, Garibaldi G, Bugarski-Kirola D, Berardo CG, Kapur S. Negative symptoms have greater impact on functioning than positive symptoms in schizophrenia: analysis of CATIE data. Schizophr Res 2012;137:147-150.

4. Ross CA, Margolis RL, Reading SA, Pletnikov M, Coyle JT. Neurobiology of schizophrenia. Neuron 2006;52:139-153.

5. Hunter R, Barry S. Negative symptoms and psychosocial functioning in schizophrenia: neglected but important targets for treatment. Eur Psychiatry 2012;27:432-436.

6. Luby ED, Gottlieb JS, Cohen BD, Rosenbaum G, Domino EF. Model psychoses and schizophrenia. Am J Psychiatry 1962;119:61-67.

7. Javitt DC, Zukin SR. Recent advances in the phencyclidine model of schizophrenia. Am J Psychiatry 1991;148:1301-1308.

8. Krystal JH, Karper LP, Seibyl JP, Freeman GK, Delaney R, Bremner JD, et al. Subanesthetic effects of the noncompetitive NMDA antagonist, ketamine, in humans. Psychotomimetic, perceptual, cognitive, and neuroendocrine responses. Arch Gen Psychiatry 1994;51:199-214.

9. Malhotra AK, Pinals DA, Adler CM, Elman I, Clifton A, Pickar D, et al. Ketamine-induced exacerbation of psychotic symptoms and cognitive impairment in neuroleptic-free schizophrenics. Neuropsychopharmacology 1997;17:141-150.

10. Labrie V, Roder JC. The involvement of the NMDA receptor D-serine/ glycine site in the pathophysiology and treatment of schizophrenia. Neurosci Biobehav Rev 2010;34:351-372.

11. Alberati D, Moreau JL, Lengyel J, Hauser N, Mory R, Borroni E, et al.
Glycine reuptake inhibitor RG1678: a pharmacologic characterization of an investigational agent for the treatment of schizophrenia. Neuropharmacology 2012;62:1152-1161.

12. Umbricht D, Alberati D, Martin-Facklam M, Borroni E, Youssef EA, Ostland M, et al. Effect of bitopertin, a glycine reuptake inhibitor, on negative symptoms of schizophrenia: a randomized, double-blind, proof-of-concept study. JAMA Psychiatry 2014;71:637-646.

13. Alphs L. An industry perspective on the NIMH consensus statement on negative symptoms. Schizophr Bull 2006;32:225-230.

14. Kirkpatrick B, Fenton WS, Carpenter WT Jr, Marder SR. The NIMHMATRICS consensus statement on negative symptoms. Schizophr Bull 2006;32:214-219.

15. Marder SR, Davis JM, Chouinard G. The effects of risperidone on the five dimensions of schizophrenia derived by factor analysis: combined results of the North American trials. J Clin Psychiatry 1997;58:538-546.

16. Haro JM, Kamath SA, Ochoa S, Novick D, Rele K, Fargas A, et al. The Clinical Global Impression-Schizophrenia scale: a simple instrument to measure the diversity of symptoms present in schizophrenia. Acta Psychiatr Scand Suppl 2003;416:16-23.

17. Nasrallah H, Morosini P, Gagnon DD. Reliability, validity and ability to detect change of the Personal and Social Performance scale in patients with stable schizophrenia. Psychiatry Res 2008;161:213-224.

18. Griffiths KM, Nakane Y, Christensen H, Yoshioka K, Jorm AF, Nakane H. Stigma in response to mental disorders: a comparison of Australia and Japan. BMC Psychiatry 2006;6:21.

19. Richards M, Hori H, Sartorius N, Kunugi H. Cross-cultural comparisons of attitudes toward schizophrenia amongst the general population and physicians: a series of web-based surveys in Japan and the United States. Psychiatry Res 2014;215:300-307.

20. Hasan A, Falkai P, Wobrock T, Lieberman J, Glenthoj B, Gattaz WF, et al. World Federation of Societies of Biological Psychiatry (WFSBP) Guidelines for Biological Treatment of Schizophrenia, part 1: update 2012 on the acute treatment of schizophrenia and the management of treatment resistance. World J Biol Psychiatry 2012;13:318-378.

21. Leucht S, Cipriani A, Spineli L, Mavridis D, Orey D, Richter F, et al. Comparative efficacy and tolerability of 15 antipsychotic drugs in schizophrenia: a multiple-treatments meta-analysis. Lancet 2013;382: 951-962.

22. Nagino K, Koh T, Harada Y. Pharmacological properties of paliperidone ER (INVEGA ${ }^{\circledR}$ ) and results of its clinical studies. Nihon Yakurigaku Zasshi 2011;137:245-254.

23. Kane J, Canas F, Kramer M, Ford L, Gassmann-Mayer C, Lim P, et al. Treatment of schizophrenia with paliperidone extended-release tablets: a 6-week placebo-controlled trial. Schizophr Res 2007;90:147-161.

24. Marder SR, Kramer M, Ford L, Eerdekens E, Lim P, Eerdekens M, et al. Efficacy and safety of paliperidone extended-release tablets: results of a 6-week, randomized, placebo-controlled study. Biol Psychiatry 2007;62:1363-1370.

25. Davidson M, Emsley R, Kramer M, Ford L, Pan G, Lim P, et al. Efficacy, safety and early response of paliperidone extended-release tablets (paliperidone ER): results of a 6-week, randomized, placebo-controlled study. Schizophr Res 2007;93:117-130.

26. Agid O, Siu CO, Potkin SG, Kapur S, Watsky E, Vanderburg D, et al. Meta-regression analysis of placebo response in antipsychotic trials, 1970-2010. Am J Psychiatry 2013;170:1335-1344.

27. Leucht S, Heres S, Davis JM. Increasing placebo response in antipsychotic drug trials: let's stop the vicious circle. Am J Psychiatry 2013;170: 1232-1234.

28. King PA, Gunn RB. Na- and Cl-dependent glycine transport in human red blood cells and ghosts. A study of the binding of substrates to the outward-facing carrier. J Gen Physiol 1989;93:321-342.

29. Ajioka RS, Phillips JD, Kushner JP. Biosynthesis of heme in mammals. Biochim Biophys Acta 2006;1763:723-736. 